\title{
Um auto de Camões (quase) redescoberto
}

\author{
Maria João Brilhante
}

0 espectáculo estreou a 18 de Março de 2004 no Teatro do Bairro Alto, numa produção da Cornucópia, com encenação de Luis Miguel Cintra, cenário e figurinos de Cristina Reis, interpretações de Cláudia

Jardim, Dinis Gomes, Duarte Guimarães, João

Lizardo, José Manuel Mendes, Luis Lima Barreto, Luis Miguel Cntra, Marina

Albuquerque, Pedro Lacerda, Ricardo Aibéo e Sofia Marques.
Luís de Camões, Filodemo, edição de José Camões, Lisboa, Cotovia, 2004, 125 pp.

Existe desde há um ano nas livrarias a mais recente edição de Filodemo, um dos três textos que Luis de Camões terá escrito para teatro. É também aquele que menos atenção suscitou até hoje e do qual apenas se sabe ter sido representado entre 1555 e 1559, na İndia.

A sua publicação na estimável colecção de Teatro da Cotovia, aproveitou e bem a simultânea representação do auto pelo Teatro da Cornucópia'. Poucas vezes acedeu ao palco, como refere José Camões, o responsável pela edição, em "Nota introdutória", e as edições existentes quase sempre o anexaram a outros textos de Camões, nas obras completas ou em antologias. Texto subestimado, portanto, mas não completamente esquecido nas sucessivas tentativas de glorificação do seu autor.

Seguindo sugestão de Paul Teyssier, que em 1987 preconizava o indispensável regresso à cópia de Francisco Correa por considerá-la mais próxima do manuscrito autógrafo desaparecido, José Camões preparou a presente edição a partir dessa cópia incluída num Cancioneiro e feita presumivelmente em 1589. Corrigidos erros, acrescentada uma cena e as rubricas existentes na primeira edição impressa de Autos e comédias feitas por António Prestes e Luis de Camões e por outros autores portugueses, publicada com a data de 1587 e desde então a única reeditada, é este o texto do auto que se oferece à leitura e aquele com o qual trabalharam os actores do Teatro da Cornucópia. Os critérios de edição, por estarem disponíveis na página do Centro de Estudos de Teatro², em cujo programa "Tesouro" esta edição se inscreve, não são aqui indicados.

0 rigor colocado na preparação da edição do auto que procurou, além do mais, estar atenta à "especificidade de objecto de teatro", como escreve José Camões, fica patente através da inclusão do resultado da pesquisa realizada durante essa preparação. São disponibilizados um Glossário de termos, cerca de duas centenas de Notas e uma Bibliografia que faz a história editorial do texto e da sua leitura. Sublinhe-se, desde logo, que este aparato é precioso para o leitor e um instrumento de trabalho incontornável para quem pretende pôr em cena o auto. Através dele é possivel resolver problemas de interpretação a vários niveis: linguístico, histórico, poético, socio-cultural, historico-literário. Não menos importante será a surpresa que provoca esta leitura iluminada naqueles que não conheciam o texto ou o julgavam criação menor na obra de Camões.

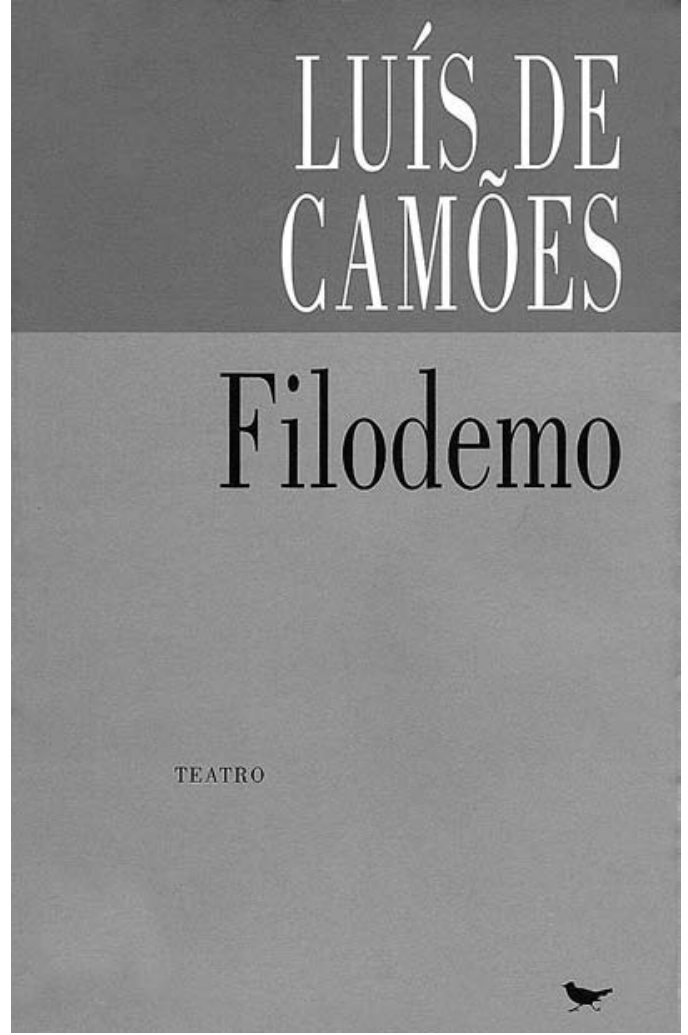

E como a memória da mais recente representação do auto estará ainda presente no leitor destas linhas, há que referir a circunstância feliz de a edição e a encenação terem caminhado a par. Se a primeira ganhou com a interpelação directa da cena e com as suas exigências materiais, a segunda viu desvendarem-se zonas textuais obscuras, descobriu determinantes de ordem estética, poética e filosófica que permitiram, por certo, uma diferente apropriação de um texto que, apesar de distante do nosso universo de valores e referências, recria situações humanas numa língua que é (e apetece fazer) nossa.

Podemos dizer que, para além da sua irónica beleza plástica, o aspecto mais notável do espectáculo residia no jogo dos actores e em como mostravam o prazer de fazer sua a língua do texto, no modo como ligavam os seus corpos àquele discurso, no entendimento da codificação que deixavam transparecer e que, em certos momentos, sublinhavam mesmo, num acordo feliz com as escolhas de Luís Miguel Cintra e de Cristina Reis. Não se tratava, por conseguinte, de simplesmente re-produzir estereótipos 


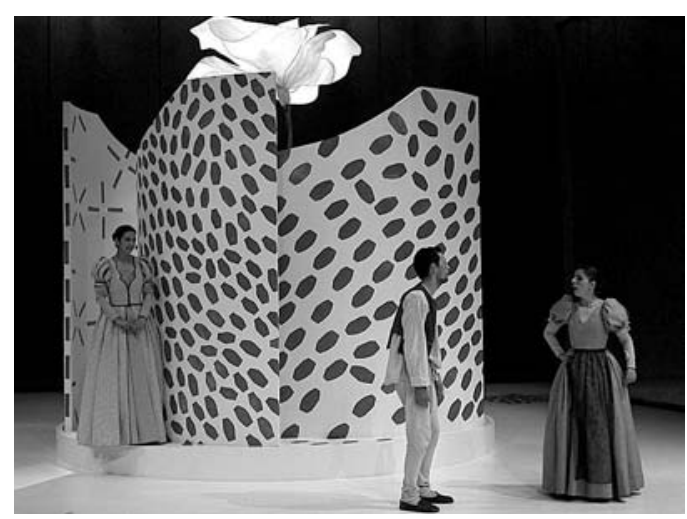

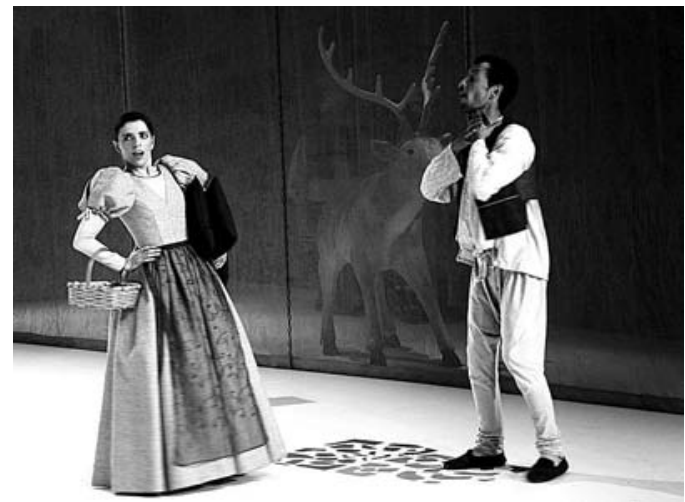

de um universo histórico-literário - reconstituição inevitavelmente estéril de uma época, que os figurinos poderiam sugerir - mas de perceber, por dentro da língua, do verso, da fala, elementos com os quais jogar, inventar, criar esse universo.

A nossa recepção do texto dependia, pois, da cumplicidade estabelecida, da produção de uma certa clarividência face àquele modelo de teatro. E isso só foi possivel porque actores, encenador e cenógrafa se apropriaram, para seu grande divertimento, das convenções presentes na tipologia de personagens, na poética amorosa, nos tópicos literários, nos códigos poéticos maneiristas, no formalismo retórico com os quais o poeta joga, e que, se não entendidos, obscurecem e gelam a cena. Em suma, o divertimento do espectáculo tornou-se divertimento do espectador que viu irradiar sensualidade onde esperava, porventura, encontrar letra morta.

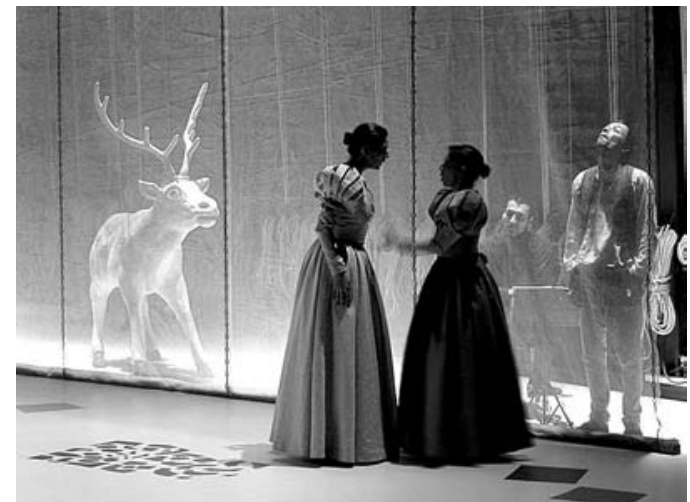

Referência bibliográfica

TEYSSIER, Paul (1992), "As duas versões do Auto de Filodemo", in Actas da V Reunião internacional de camonistas (São Paulo, 20-24 de Julho de 1987), S. Paulo, Universidade de S. Paulo, Faculdade de Filosofia, Letras e Ciências Humanas, pp. 419-436.

\section{Filodemo}

de Luis de Camões, enc. Luis Miguel Cintra, Teatro da Cornucópia, 2004

(Sofia Marques, Pedro Lacerda e Marina Albuquerque) fot. Paulo Nuno.

Filodemo,

de Luis de Camões, enc. Luis Miguel Cintra, Teatro da Cornucópia, 2004 (Marina Albuquerque e Pedro Lacerda), fot. Paulo Nuno.

\section{Filodemo,}

de Luis de Camões, enc. Luis Miguel Cintra, Teatro da Cornucópia, 2004

(Sofia Marques, Marina Albuquerque e Pedro Lacerda), fot. Paulo Nuno. 